\title{
The role of gender in compliance and attendance at an outpatient clinic for type 2 diabetes mellitus in Trinidad
}

\author{
Feaz Babwah, ${ }^{1}$ Soraiya Baksh, ${ }^{1}$ Leandra Blake, ${ }^{1}$ Janine Cupid-Thuesday, ${ }^{1}$ \\ lan Hosein, ${ }^{1}$ Anneela Sookhai, ${ }^{1}$ Celia Poon-King, ${ }^{2}$ and Gerard Hutchinson ${ }^{3}$
}

Suggested citation

Babwah F, Baksh S, Blake L, Cupid-Thuesday J, Hosein I, Sookhai A, Poon-King C, Hutchinson G. The role of gender in compliance and attendance at an outpatient clinic for type 2 diabetes mellitus in Trinidad. Rev Panam Salud Publica. 2006;19(2):79-84.

\begin{abstract}
Objectives. To explore the association between gender and (1) attendance and (2) compliance with treatment in a population of patients with diabetes who attended outpatient clinics in the island of Trinidad (Trinidad and Tobago).

Methods. A cross-sectional study was conducted with a sample of 360 patients who met the selection criteria. Simple consecutive sampling and a questionnaire were used to interview clinic attendees at two urban clinics in east and south Trinidad.

Results. $74.2 \%$ (267) of the participants were women. A higher percentage of women than men were unemployed (79.4\% vs. 59.1\%, P <0.001). Men were more likely to consume alcohol $(26.9 \%$ vs. $11.6 \%, \mathrm{P}<0.001)$ and smoke cigarettes $(20.4 \%$ vs. $5.6 \%, \mathrm{P}<0.001)$. Women were more compliant than men regarding diet $(39.3 \%$ vs. $22.6 \%, \mathrm{P}<0.005)$ and prescribed medication ( $71.9 \%$ vs. $65.6 \%, \mathrm{P}<0.04)$. Women were more satisfied than men with dispensary $(81.3 \%$ vs. $71.0 \%, \mathrm{P}<0.04)$ and clinic conditions $(92.1 \%$ vs. $84.9 \%, \mathrm{P}<0.05)$.

Conclusions. More women attended the clinic, and their compliance with the treatment regimen was better than in men. The latter were more likely to engage in health risk behaviors such as drinking and smoking. Efforts focused on men with diabetes mellitus in Trinidad and Tobago are needed to encourage greater compliance.
\end{abstract}

Keywords Diabetes mellitus, gender identity, patient compliance.

Diabetes mellitus is defined by the Pan American Health Organization (PAHO) as a chronic metabolic disease characterized by hyperglycemia and by disturbances of carbohydrate, fat, and protein metabolism. It is associ- ated with absolute or relative deficiency in the secretion or action of the hormone insulin (1).

Type 2 diabetes mellitus, also known as non-insulin-dependent diabetes mellitus, is the more common form of

\footnotetext{
1 Fourth year Medical Student, Faculty of Medical Sciences, University of the West Indies, St. Augustine, Trinidad and Tobago.

2 Public Health and Primary Care Unit, Faculty of Medical Sciences, University of the West Indies, St. Augustine, Trinidad and Tobago.

3 Psychiatry Unit, Faculty of Medical Sciences, University of the West Indies, St. Augustine, Trinidad
}

the disease, representing around 90\% of all diabetes cases (2). In type 2 diabetes, either the $\beta$-cells of the pancreas do not produce enough insulin or the cells of the body become increasingly resistant to insulin and hence fail to respond to the hormone, resulting in hyperglycemia (3).

Diabetes is reaching epidemic proportions around the world, with about 150 million people currently affected (4). In the year 2000 it was estimated that 19 million people from Latin 
America and the Caribbean suffered from the disease (2). This number is projected to rise to 40 million by the year 2025 (2). As an underlying cause of death, diabetes accounts for more than 40000 deaths per year in Latin America and the Caribbean (5).

The 2001 PAHO Health Analysis classified diabetes mellitus as the thirdranking cause of death in men and the second-ranking cause of death in women in Trinidad and Tobago (6). This disease is of great concern since approximately one-third of all persons with diabetes are undiagnosed and half of the newly-diagnosed persons were already affected by chronic complications at the time of their diagnosis (5).

Within the primary care setting, a major indicator of treatment-seeking behavior is clinic attendance, and nonattendance is a significant problem at diabetic clinics (7). In the United Kingdom, however, among patients with type 1 diabetes mellitus, no gender bias in terms of clinic attendance was found (7). It would therefore be interesting to determine whether in Trinidad and Tobago clinic attendance is evenly distributed between men and women with diabetes mellitus, particularly since the incidence of diabetes mellitus in the two major ethnic groups in this country does not suggest any gender differences (8).

Research suggests that people with diabetes are poorly compliant with dietary and exercise recommendations and that primary noncompliance with medication is common (9). Efforts to identify some of the demographic variables that may affect compliance must begin with attendance of clinic appointments. There is limited research in this area in the Caribbean region, and given the morbidity and mortality associated with diabetes mellitus, it is important that determinants of clinic attendance and compliance are established. This information may make implementation of diabetes disease management programs and the promotion of compliance more effective (10).

Even with the implementation of comprehensive management plans, the availability of medication, and efficient outpatient clinic services, it is im- portant to determine whether any segment of the population is less likely to attend clinic services or be less compliant with the medication regimen and lifestyle recommendations provided. The information obtained from the present study is therefore potentially useful for the development of interventional strategies that can be specifically targeted to improve patient compliance and modify lifestyle behavior in Latin America and the Caribbean.

\section{METHODS}

\section{Setting}

The study was conducted in two urban clinics in east and south Trinidad: the medical outpatient clinic at the Eric Williams Medical Sciences Complex and the diabetes outpatient clinic at San Fernando General Hospital, which serve the population of San Fernando, Trinidad and Tobago's second largest city. The population of Trinidad and Tobago is 1.3 million, and these two clinics serve a combined population of 700000 people (11). It is estimated that in the population served by these clinics there may be approximately 40000 people with diabetes mellitus, many of whom are undiagnosed (2).

\section{Study design}

This cross-sectional study was conducted at the Eric Williams Medical Sciences Complex (EWMSC) and at San Fernando General Hospital during the months of June and July, 2003. Because of the limited number of patients seen on a typical clinic day, the short time available to conduct our study and the broad exclusion criteria, the sampling method used in this study was simple consecutive sampling.

\section{Sample}

The criteria for participation in the study were being more than 13 years of age, attendance of the diabetes outpatient clinic at either of the two insti- tutions, and clinical diagnosis of type 2 diabetes mellitus. Both clinics are designed for the treatment of individuals with diabetes mellitus only. Individuals with type 1 diabetes, first-time clinic attendees, persons with fewer than 3 visits to the clinic, volunteers who were pregnant, and individuals who were mentally incapacitated or who had severe speech or hearing difficulties were excluded from the study.

The sample size was determined to be approximately 371 volunteers. The assumptions used to calculate this number were: (1) $10 \%$ of the adult population have type 2 diabetes mellitus, (2) the estimated male/female ratio for clinic attendees would be $30: 70$, based on observation of the populations seen at the two sites, (3) $10 \%$ of the population surveyed would refuse to participate, and (4) $5 \%$ of the questionnaires filled out would be incomplete and hence unusable.

\section{Data collection}

Approval was obtained from the Ethics Committee of the Faculty of Medical Sciences of the University of the West Indies, St. Augustine, and samples were taken by visiting the hospitals during the period from 10 June to 29 July, 2003, on scheduled clinic days. Six trained investigators were responsible for data collection.

The objectives of the study were explained and written consent was obtained from each research candidate who met the inclusion criteria. The questionnaire was designed de novo with simple, concise questions to avoid ambiguity and to minimize the time spent on each interview. It was pretested at the EWMSC on 27 May, 2003, and at the San Fernando General Hospital on 3 June, 2003, and no changes to the questionnaire were made after pretesting. The instrument was administered by the interviewer in a convenient area of the clinic away from the other patients to minimize biased responses and ensure privacy. Participation in the study was completely voluntary and patients had the right to withdraw from the project at any time. 
An identification number was assigned to each questionnaire and no identifying information was recorded on the questionnaire. All completed questionnaires and information sheets were stored in a locked file cabinet, and at the end of the study all identifying information was destroyed to ensure that confidentiality was maintained.

Demographic data comprising gender, age group, ethnicity, level of education and employment status were recorded from the questionnaire. Health risk behaviors (smoking and alcohol consumption) were also recorded because both of these are related to poorer health outcomes for patients with diabetes mellitus, and smoking in particular greatly increases the risk of vascular complications.

Smokers were classified as persons who smoked $\geq 1$ cigarette per occasion. Nonsmokers were persons who denied smoking $\geq 1$ cigarette per occasion (12).

Drinkers were defined according to the consumption of 14 or more drinks per week or $>4$ drinks per occasion for men, and 7 or more drinks per week or $>3$ drinks per occasion for women. A standard drink unit was determined to be $12 \mathrm{oz}$ (approx. $340 \mathrm{~mL}$ ) beer (5\% alcohol) or $1 \frac{1}{2} \mathrm{oz}$ (approx. $43 \mathrm{~mL}$ ) 80proof liquor (40\% alcohol). Nondrinkers were persons who did not drink or who consumed smaller amounts of alcoholic beverages than the cutoff values explained above (13).

A person was considered compliant with respect to diet if he answered yes to the items that inquired whether he had received or sought dietary counseling and whether he consumed either 3 meals and 2 snacks or 2 meals and 3 snacks per day. A snack was defined as a healthy, quick portion of food consumed between meals (e.g., 1 slice of whole wheat bread with a tablespoon of peanut butter or one small piece of fruit) (14). This compliance criterion did not exclude people from the study but was used to identify those who were thought to be likely to follow the dietary instructions given to them.

Values for blood pressure and blood cholesterol levels were obtained from the clinic notes, and data for clinic at- tendance and appointment-keeping were obtained from the questionnaire and confirmed by consulting the patient's clinic notes.

\section{Statistical analysis}

The Statistical Package for Social Sciences (SPSS v. 10.0) was used for data entry and analysis. Frequencies and chi-squared values were calculated, and the significance level was set at 0.05 with a power of $90 \%$.

Because of the difficulty in obtaining reliable data for clinic attendees' socioeconomic status, duration of disease and general health status, it was impossible to include these factors in the analysis.

\section{RESULTS}

Of the 412 type 2 diabetes clinic attendees approached for our study, 52 $(12.6 \%)$ refused to participate (18 men, 34 women). This gave a response rate of $87.4 \%$. The study population therefore consisted of 360 volunteers: 267
(74.2\%) women and $93(25.8 \%)$ men. Review of the population of 1125 attendees seen over the entire year reflected this same gender distribution.

The demographic profile of individuals in the sample population is presented in Table 1. Most patients with type 2 diabetes were between the ages of 45 and 64 years $(218,60.6 \%)$. For the different age groups, the greatest percentage of men $(34.4 \%)$ fell into the 55-64 year age group and the greatest percentage of women $(31.8 \%)$ was seen in the 45-54 year age group. Neither of these gender differences was significant $(P=0.241)$.

An interesting finding was that the percentage of patients of East Indian descent was exactly the same for both genders: $62(66.7 \%)$ men and 178 (66.7\%) women $(P=0.891)$.

More women were educated up to the primary level $(64.4 \%)$, and more men $(41.9 \%)$ reported receiving education up to the secondary level $(24.3 \%$, $P<0.01)$. Most of the population interviewed $(267,74.2 \%)$ was unemployed, with unemployment being significantly more frequent among women (79.4\%) than men $(59.1 \%, P<0.001)$.

TABLE 1. Demographic characteristics of patients with type 2 diabetes mellitus seem at diabetes outpatient clinics at the Eric Williams Medical Sciences Complex (EWMSC) and San Fernando General Hospital, Trinidad, June-July 2003

\begin{tabular}{|c|c|c|c|c|c|}
\hline \multirow[b]{2}{*}{ Parameters } & \multicolumn{2}{|c|}{$\begin{array}{c}\text { Men } \\
(n=93)\end{array}$} & \multicolumn{2}{|c|}{$\begin{array}{l}\text { Women } \\
(n=267)\end{array}$} & \multirow[b]{2}{*}{$P$ value } \\
\hline & No. & Percentage & No. & Percentage & \\
\hline \multicolumn{6}{|l|}{ Age group (years) } \\
\hline $25-34$ & 0 & 0.0 & 13 & 4.9 & 0.241 \\
\hline $35-44$ & 14 & 15.1 & 31 & 11.6 & \\
\hline $45-54$ & 25 & 26.9 & 85 & 31.8 & \\
\hline $55-64$ & 32 & 34.4 & 76 & 28.5 & \\
\hline $65-74$ & 18 & 19.4 & 48 & 18.0 & \\
\hline Over 75 & 4 & 4.3 & 14 & 5.2 & \\
\hline \multicolumn{6}{|l|}{ Ethnicity } \\
\hline African origin & 24 & 25.8 & 65 & 24.3 & 0.891 \\
\hline East Indian origin & 62 & 66.7 & 178 & 66.7 & \\
\hline Mixed & 7 & 7.5 & 24 & 9.0 & \\
\hline \multicolumn{6}{|c|}{ Highest level of education } \\
\hline None & 4 & 4.3 & 7 & 2.6 & $<0.01$ \\
\hline Primary & 43 & 46.2 & 172 & 64.4 & \\
\hline Secondary & 39 & 41.9 & 65 & 24.3 & \\
\hline Tertiary & 7 & 7.5 & 23 & 8.6 & \\
\hline \multicolumn{6}{|l|}{ Employment status } \\
\hline Unemployed & 55 & 59.1 & 212 & 79.4 & $<0.001$ \\
\hline Employed & 38 & 40.9 & 55 & 20.6 & \\
\hline
\end{tabular}


TABLE 2. Compliance and treatment-seeking behavior among patients with type 2 diabetes mellitus seen at diabetes outpatient clinics at the Eric Williams Medical Sciences Complex (EWMSC) and San Fernando General Hospital, Trinidad, June-July 2003

\begin{tabular}{|c|c|c|c|c|c|}
\hline \multirow[b]{2}{*}{ Parameters } & \multicolumn{2}{|c|}{$\begin{array}{c}\text { Men } \\
(n=93)\end{array}$} & \multicolumn{2}{|c|}{$\begin{array}{l}\text { Women } \\
(n=267)\end{array}$} & \multirow[b]{2}{*}{$P$ value } \\
\hline & No. & Percentage & No. & Percentage & \\
\hline Alcohol consumed & 25 & 26.9 & 31 & 11.6 & $<0.001$ \\
\hline Current smoker & 19 & 20.4 & 15 & 5.6 & $<0.001$ \\
\hline Exercises regularly & 58 & 62.4 & 188 & 70.4 & 0.151 \\
\hline Compliant with diet & 21 & 22.6 & 105 & 39.3 & $<0.005$ \\
\hline High blood cholesterol & 38 & 40.9 & 97 & 36.3 & 0.437 \\
\hline \multicolumn{6}{|l|}{$\begin{array}{l}\text { Reported frequency of kept clinic } \\
\text { appointments }\end{array}$} \\
\hline Always & 64 & 68.8 & 166 & 62.2 & 0.478 \\
\hline Most times & 26 & 28.0 & 93 & 34.8 & \\
\hline Sometimes & 3 & 3.2 & 8 & 3.0 & \\
\hline \multicolumn{6}{|l|}{$\begin{array}{l}\text { Reported make-up for missed } \\
\text { appointments }\end{array}$} \\
\hline Did not miss & 41 & 44.1 & 121 & 45.3 & 0.758 \\
\hline Always & 40 & 43.0 & 101 & 37.8 & \\
\hline Most times & 6 & 6.5 & 22 & 8.2 & \\
\hline Sometimes & 6 & 6.5 & 23 & 8.6 & \\
\hline \multicolumn{6}{|l|}{ Reported satisfaction with } \\
\hline Doctor & 81 & 87.1 & 246 & 92.1 & 0.147 \\
\hline Nurse & 86 & 92.5 & 255 & 95.5 & 0.260 \\
\hline Dispensary & 66 & 71.0 & 217 & 81.3 & $<0.04$ \\
\hline Clinic conditions & 79 & 84.9 & 246 & 92.1 & $<0.05$ \\
\hline \multicolumn{6}{|l|}{$\begin{array}{l}\text { Reported taking medication as } \\
\text { prescribed }\end{array}$} \\
\hline Always & 61 & 65.6 & 192 & 71.9 & $<0.04$ \\
\hline Most times & 25 & 26.9 & 70 & 26.2 & \\
\hline Sometimes & 7 & 7.5 & 5 & 1.9 & \\
\hline Herbal/Alternative medication & 8 & 8.6 & 12 & 4.5 & 0.136 \\
\hline Self-monitoring of blood glucose level & 50 & 53.8 & 113 & 42.3 & 0.269 \\
\hline Self-monitoring of blood pressure & 23 & 24.7 & 52 & 19.5 & 0.632 \\
\hline Special care of feet & 87 & 93.5 & 242 & 90.6 & 0.389 \\
\hline
\end{tabular}

Table 2 presents the relationship between gender and factors related to patient compliance. After being diagnosed as having type 2 diabetes mellitus, women were less likely to consume alcohol (11.6\%) compared to their male counterparts $(26.9 \%, P<$ 0.001). Women were also significantly less likely to be current smokers (5.6\%) than men $(20.4 \%, P<0.001)$. No significant difference in regular exercise habits between the two genders was observed, although a smaller percentage of men $(62.4 \%)$ than women (70.4\%, $P=0.151)$ reported that they exercised regularly.

With respect to dietary recommendations, women were more compliant than men $(39.3 \%$ vs. $22.6 \%, P<0.005)$. There was no significant difference between genders with regard to levels of ternative medication than women $(4.5 \%)$, but the difference was not significant $(P=0.136)$. The use of alternative or herbal medications is indicative of poorer compliance, as these are used as substitutes for medications prescribed at the clinic.

Men reported higher frequencies than women for self-monitoring of blood glucose levels (53.8\% vs. $42.3 \%$ ) and blood pressure ( $24.7 \%$ vs. $19.5 \%)$, and for special care of feet $(93.5 \%$ vs. $90.6 \%$ ). However, none of these differences were statistically significant $(P=0.269, P=0.632$ and $P=0.389$, respectively).

\section{DISCUSSION}

Our study sought to explore the associations between gender on the one hand and treatment-seeking behavior and compliance with treatment on the other, in outpatient clinic attendees with type 2 diabetes mellitus on the island of Trinidad. There were approximately three times as many women as men with type 2 diabetes mellitus among clinic attendees. This suggests that significantly more women than men attended outpatient clinics. It is likely that this attendance ratio far exceeds the gender ratio for the population prevalence of type 2 diabetes mellitus. Findings from the United States suggest a disparity of approximately $10 \%-15 \%$ in favor of women (15), although an earlier study in Trinidad and Tobago reported no significant gender differences in the incidence of type 2 diabetes mellitus (8). In Greece the prevalence was higher in men $(7.6 \%)$ than in women (5.9\%) (16). Taken together, these findings suggest that there is no marked gender difference in the incidence and prevalence of type 2 diabetes mellitus. If clinic attendance and compliance were associated with greater survival, then women with the disease would be expected to live longer. However, alternative explanations for the greater clinic attendance by women are discussed below.

Because a significant majority of women were unemployed, they were more likely to have time to attend ap- 
pointments during the clinic opening hours and to wait at the clinic for long periods (waits can be typically prolonged at public institutions). The greater level of satisfaction reported by women with respect to clinic conditions and dispensary services may also be related with the larger proportion of women among clinic attendees. Differences in gender representation at the outpatient clinics we studied were not significantly associated with age, ethnicity or level of education. Because men are reported to have more complications (5), they might attend preferentially clinics that treat these complications (such as ophthalmology and renal clinics). Our findings, however, still point to a difference between genders, which may occur because men are less compliant in the early stages of their illness.

One important public health issue raised by these findings is that men seem less likely to utilize public health services than women. This concurs with a previous study conducted by the World Health Organization in 1998 that indicated that men are less inclined to engage in help-seeking behaviors (17). As a result, they remain unaware of the presence of type 2 diabetes mellitus until complications begin to occur (5). This difference in help-seeking behavior may explain our findings of a marked gender difference and may also explain why the men who did attend the clinic regularly were more likely to monitor their blood sugar and blood pressure and to take special care of their feet.

The greater prevalence of smoking and alcohol consumption among men with diabetes also predisposes men to a wider range of health risks, namely hypertension and cerebrovascular and cardiovascular disease, and may contribute to the lower life expectancy of men compared to women (6). This risk is further compounded by their reluctance to seek appropriate health care services and inclination to be less compliant.

Our findings show that women were more likely to be compliant with dietary regimens and more likely to take medication as prescribed. One possible reason for this is that women with diabetes are more likely to attend a clinic, where they receive more frequent counseling and follow-up management. It would appear that women were more likely to be in contact with health services and made more visits to the clinic, and thus had more contact with care providers.

A potential limitation in this study is the possibility of inaccuracies in responses from the participants. We could not corroborate all of the patients' responses, so there might have been some reporting bias.

The populations served by these two clinics are roughly representative of the general population with the exception of ethnicity, since the proportion of persons of East Indian origin in our sample is higher than the figure for the population of Trinidad and Tobago. However, diabetes mellitus is more common in the East Indian population (8) and our sample can therefore be considered representative of the population with type 2 diabetes mellitus in Trinidad and Tobago.

Our initial choice of medical institutions was aimed at providing a sample with demographic characteristics that were representative of the population of diabetes outpatient clinic users in Trinidad and Tobago. Socioeconomic status was not considered, although this factor has been shown to be associated with treatment-seeking behavior since people of lower socioeconomic status are less likely to use services than those in the upper classes (15). Another limitation is the lack of multivariate analysis with data for socioeconomic status, general health status and duration of disease to establish the influence of these factors on diabetes clinic attendance and treatment compliance. In view of these limitations, our findings and conclusions need to be interpreted with caution.

Nevertheless, our results suggest that women in Trinidad and Tobago seek help at diabetes clinics more often than men, and are more compliant with treatment. Future research is needed to explore other factors that might explain why women are more compliant and attend diabetes outpatient clinics more assiduously than men. In this Caribbean society, in which men provide significant support to their households and generate substantial contributions to the country's productivity, future health promotion and prevention strategies should be tailored to target men and boys with type 2 diabetes. The long-term repercussions of disabling complications could be minimized by encouraging men to be more health conscious and compliant with treatment.

Acknowledgments. We acknowledge the support and contribution of Rudy Singh, Statistician of the Public Health and Primary Care Unit, Faculty of Medical Sciences, University of the West Indies. Appreciation is expressed to our sponsor, Wyeth Ayerst, whose contribution facilitated the preparation of materials and data gathering. We also wish to thank the medical staff and the patients of the diabetes outpatient clinics at the EWMSC and San Fernando General Hospital for accommodating and assisting in the process of data collection.

\section{REFERENCES}

1. Pan American Health Organization. Diabetes in the Americas. Diabetes mellitus: fact sheet with country data [Internet site]. Available at: http://www.paho.org/english/hcp/hcn/ imp/dia-info.html. Accessed 1 September 2003.
2. Pan American Health Organization. Diabetes in the Americas. Epidemiol Bull. 2001; June; 22(2):1-4. Available at: URL: http://www. paho.org/english/sha/be_v22n2-diabetes. htm.
3. Kaufman FR. Type 2 diabetes mellitus in children and youth: a new epidemic. J Pediatr Endocrinol Metab. 2002; May 15(Suppl 2):737-44.

4. Diabetes Association of Trinidad and Tobago. Diabetes. Focus on DATT 2002;Apr 17:1-6. 
5. Barcelo A, Vovides Y. The Pan American Health Organization and World Diabetes Day. [Editorial]. Pan Am J Public Health. 2001; 10(5): 297-9.

6. Pan American Health Organization. Special Program for Health Analysis based on: World Population Prospects: the 1998 Revision, United Nations. Data updated for 2001. [Internet site]. Available at: http://www.paho. org/English/DD/AIS/cp_780htm. Accessed 25 November 2004.

7. Dyer PH, Lloyd CE, Lancashire RJ, Bain SC, Barnett $\mathrm{AH}$. Factors associated with clinic non-attendance in adults with type 1 diabetes mellitus. Diabet Med. 1998;Apr 15(4):339-43.

8. Miller GJ, Maude GH, Beckles GL. Incidence of hypertension and non insulin dependent diabetes mellitus and associated risk factors in a rapidly developing Caribbean community; The St James survey, Trinidad. J Epidemiol Community Health. 1996;50(5):497-504

9. Cradock S. Helping patients to improve selfmanagement of diabetes. Heart. 2004; 90 Suppl 4:iv36-8; discussion iv39-40.
10. Zgibor JC, Rao H, Wesche-Thobaben J, Gallagher N, McWilliams J, Korytkowski MT. Improving the quality of diabetes care in the primary care practice. J Health Qual. 2004;26(4): 14-21.

11. Trinidad and Tobago, Central Statistical Office. Population census of Trinidad and Tobago 2000. Ministry of Planning and Development, Government Printery, Port of Spain, Trinidad; 2003.

12. Grol MEC, Halabi Y, Gerstenbluth I, Alberts JF, O'Neil JO. Lifestyle in Curacão: smoking, alcohol consumption, eating habits and exercise. West Indian Med J. 1997;46(1):8-14.

13. United States of America, US Department of Health and Human Services, Public Health Service, National Institutes of Health, National Institute on Alcohol Abuse and Alcoholism. The physician's guide to helping patients with alcohol problems; 1995. [Internet site]. Available at: http://www.moderation.org/otherlim. html. Accessed 21 July 2003.

14. Diabetic meal plan and exchange lists. Manual of nutrition and dietetic practice for the
Caribbean. Mona, Kingston (Jamaica): Caribbean Food and Nutrition Institute; 1997.

15. Pan American Health Organization. Health in the Americas, 1998. Washington, D.C.: PAHO; 1998: Pp. 175-6 (Diseases or Health Impairments, vol. 1), Pp. 484-89 (Trinidad and Tobago, vol. 2).

16. Panagioptakos DB, Pitsavos C, Chrysohoou C, Stefanadis C. The epidemiology of type 2 diabetes mellitus in Greek adults: the ATTICA study. Diabet Med. 2005;22(11):1581-8.

17. World Health Organization. Gender and health. Geneva: WHO; 1998. (Technical paper).

Manuscript received on 31 May 2005. Revised version accepted for publication on 9 December 2005

RESUMEN Objetivos. Explorar la asociación entre el género y 1) la asistencia a consultas y 2) el cumplimiento del tratamiento en una población de pacientes con diabetes sacarina (mellitus) atendida en clínicas ambulatorias de la isla de Trinidad (en Trinidad y Tabago).

El papel del género en el cumplimiento del tratamiento y en la asistencia a dos clínicas ambulatorias para pacientes con diabetes sacarina en Trinidad

\author{
Palabras clave
}

Métodos. Se llevó a cabo un estudio transversal con una muestra de 360 pacientes que llenaron los requisitos de inclusión. Se realizó un muestreo sencillo de pacientes consecutivos y se aplicó un cuestionario para entrevistar a personas atendidas en dos clínicas ambulatorias urbanas del oriente y sur de Trinidad.

Resultados. De los participantes, 74,2\% eran mujeres. En términos porcentuales, más mujeres que hombres estaban sin empleo $(79,4 \%$ frente a $59,1 \% ; P<0,001)$. Los hombres mostraron una mayor tendencia que las mujeres a consumir alcohol $(26,9 \%$ frente a $11,6 \% ; P<0,001)$ y a fumar cigarrillos $(20,4 \%$ frente a $5,6 \% ; P<0,001)$. Las mujeres observaron más el régimen alimentario que los hombres $(39,3 \%$ frente a $22,6 \%$; $P<0,005)$ y se ciñeron más que estos a los medicamentos prescritos $(71,9 \%$ frente a $65,6 \% ; P<0,04)$. Las mujeres se mostraron más satisfechas que los hombres con las condiciones imperantes en los dispensarios $(81,3 \%$ frente a $71,0 \% ; P<0,04)$ y clínicas $(92,1 \%$ frente a $84,9 \% ; P<0,05)$.

Conclusiones. Más mujeres que hombres asistían a la clínica y el acatamiento del régimen terapéutico fue mayor entre las mujeres que entre los hombres. Estos se mostraron más propensos que las mujeres a incurrir en conductas peligrosas para la salud, tales como beber y fumar. Se necesitan intervenciones dirigidas hacia los hombres con diabetes sacarina en Trinidad y Tabago a fin de fomentar un mayor cumplimiento del tratamiento prescrito.

Diabetes mellitus, identidad de género, cooperación del paciente. 